\begin{abstract}
INTRODUCTION: Helicobacter pylori is one of the main causes of gastroduodenal diseases, such as chronic gastritis and peptic ulcer. It has been shown that eosinophils increase in the stomach in $H$. pylori infection. Eosinophilic cationic protein (ECP) is a cytotoxic molecule secreted by the activated eosinophils. However, there are no sufficient data about the role of ECP in $H$. pylori infection and its effect on ulcer development. In this study we investigated the gastric eosinophilic infiltration, gastric juice and serum ECP levels in patients with chronic gastritis and gastric ulcer associated with $H$. pylori.

Materials and methods: Forty-four $H$. pylori-positive and $20 \mathrm{H}$. pylori-negative patients who underwent upper gastrointestinal system endoscopy after admitting with dyspeptic complaints were enrolled in the study. Twenty-one of the $\boldsymbol{H}$. Pylori-positive patients had gastric ulcer while 23 patients had none. During endoscopy, multiple gastric biopsies and juices were taken. In gastric biopsies, $H$. pylori and eosinophilic infiltration were assessed. Additionally, gastric juice and serum ECP levels were measured.

Results: Eosinophil infiltration, gastric juice ECP levels, and gastric juice/serum ECP ratios in the $H$. pylori-positive group were greater than in the $H$. pylori-negative group $(p<0.01)$. There was no statistically significant difference regarding serum ECP levels between the two groups $(p>0.05)$. When $H$. pylori-positive patients were compared with regard to gastric ulcer presence, however, there was no significant difference in gastric eosinophil infiltration, gastric juice ECP levels, serum ECP levels, and gastric juice/serum ECP ratios $(p>0.05)$.

Conclusion: The results of this study suggest that eosinophils and eosinophil-released ECP may contribute to inflammatory changes seen in chronic gastritis, whereas there is no proof that they play a role in ulcer development.
\end{abstract}

Key words: Helicobacter pylori, Gastric ulcer, Eosinophil, Eosinophil cationic protein, Gastric juice, Serum

\section{Eosinophil infiltration, gastric juice and serum eosinophil cationic protein levels in Helicobacter pylori-associated chronic gastritis and gastric ulcer}

\author{
Selim Aydemir ${ }^{1, C A}$, Isak Ozel Tekin², \\ Gamze Numanoglu ${ }^{3}$, Ali Borazan ${ }^{4}$ and \\ Yucel Ustundag ${ }^{1}$
}

${ }^{1}$ Department of Gastroenterology, ${ }^{2}$ Department of Immunology, ${ }^{3}$ Department of Pathology, and ${ }^{4}$ Department of Internal Medicine, Zonguldak Karaelmas University, Faculty of Medicine, Ic Hastaliklari ABD, Gastroenteroloji BD, 67800 Zonguldak, Turkey

\author{
${ }^{\mathrm{CA}}$ Corresponding Author \\ Tel: +90372 2576169 \\ Fax: +90372 2610155 \\ E-mail: selimaydemir@hotmail.com
}

\section{Introduction}

Helicobacter pylori is one of the main causes of gastroduodenal diseases, such as chronic gastritis and peptic ulcer. In addition, it is closely associated with gastric carcinoma and gastric B-cell mucosa-associated lymphoid tissue lyphoma. ${ }^{1-4}$ H. pylori causes chronic gastritis in all patients whereas only a small proportion of patients infected with this microorganism develop a peptic ulcer. ${ }^{5}$ Inflammatory response is pivotal in the epithelial dysfunction and mucosal injury caused by H. pylori. H. pylori leads to mucosal increases in many proinflammatory and immunoregulatory cytokines. ${ }^{6-8}$

Eosinophils are involved in a broad range of diseases such as allergic, inflammatory, and malignant disorders. ${ }^{9-11}$ Several recent studies focused on the function of eosinophils in gastrointestinal disease. ${ }^{10,12,13}$ They are present only in small amounts in healthy gut mucosa. ${ }^{14,15}$ Their presence has been considered to be a protective mechanism against bacteria and parasites. ${ }^{11}$ The specific granules of the eosinophils contain a number of highly cationic proteins. ${ }^{16,17}$ One of the very important of these is the eosinophil cationic protein (ECP). They are markedly cationic proteins with cytotoxic capacities probably leading to tissue destruction as well as modulators of the immune response. ${ }^{18,19}$ There is increasing evidence that eosinophils are functionally involved in the pathophysiology of various inflammatory disorders of the gut. ${ }^{12,20}$

It has been showed that eosinophils increase in the stomach in $H$. pylori infection..$^{21-23}$ However, there are not sufficient studies about the role of ECP 
in H. pylori infection and its effect on ulcer development. We investigated in this study gastric eosinophil infiltration, gastric juice and serum ECP levels in patients with chronic gastritis and gastric ulcer associated with $H$. pylori.

\section{Research design and methods}

\section{Patients}

In total, $44 \mathrm{H}$. pylori-positive patients above the age of 20 years who underwent endoscopy in the gastroenterology laboratory because of dyspeptic complaints (group 1) were enrolled into the study. The patients were divided into two subgroups according to the presence of a gastric ulcer (group 1a, ulcer present; group $1 \mathrm{~b}$, ulcer absent). As the control group we selected $20 \mathrm{H}$. pylori-negative patients admitted with dyspeptic complaints who were gastric ulcer negative (group 2). Exlusion criteria were prior eradication therapy for $H$. pylori, anti-ulcer drug use within the past 1 month, gastrointestinal system and other organ malignancies, inflamatuar and infectious diseases, and prior gastric surgery.

\section{Endoscopic procedure}

Gastroduodenal endoscopic examination was performed following overnight fasting using a Pentax EG2930K (Asahi Optical, Tokyo, Japan). In each patient, $5 \mathrm{~cm}^{3}$ of gastric juice, obtained during endoscopy through a sterilised tube fitted in the operation channel of the gastroscope, were collected. For the histopathological examination, multiple biopsies from the antrum and the corpus were taken. The biopsy samples were sent to the pathology laboratory for examination in 10\% buffered formalin.

\section{Assessment of the state of $H$. pylori infection}

The state of $H$. pylori infection was assessed histologically. The biopsy specimens were fixed in 10\% formalin and embedded in paraffin. The precense of H. pylori was determined by Giemsa staining as the presence of typical gently spiralled or curved bacteria. When at least one of the biopsies of each patient yielded a positive result, the patient was considered positive for $H$. pylori.

\section{Histological assesment eosinophil infiltration}

Sections were also stained with hematoxylin and eosin. For each section, five superficial fields $(\times 400$ magnification) were randomly selected; eosinophils were individually counted by the same investigator and a mean score between five fields was obtained from each patient. ${ }^{21}$ The hematoxylin and eosin- stained specimen was given one overall score from 0 to 3 for eosinphil infiltration $(0=$ no eosinophil infiltration, $1=$ mild or patchhy eosinphil infiltration, $2=$ moderate eosinphil infiltration, $3=$ marked, confluent eosinphil infiltration).

\section{Serum and gastric juice ECP measurement}

Sera were obtained in a fasting state before endoscopy. Serum and gastric juice ECP levels were measured with a fluoroenzymeimmunoassay kit and a UNICAP device (Pharmacia\&Upjohn, Uppsala, Sweden).

\section{Statistical analysis}

Results are expressed as the mean \pm standard deviation. In the comparison between groups, statistically significant differences were assessed by the Student $t$-test and the Mann-Whitney U-test. $P<0.05$ was considered statistically significant.

\section{Results}

When the patients were divided into two groups according to $H$. pylori presence, group 1 had a total of 44 patients ( 25 males and 19 females). The mean age of the patients was $43.2 \pm 11.3$ years. Group 2 included a total of 20 patients (11 males and nine females). In this group the mean age was $42.5 \pm 10.1$ years. The age and sex distribution had an insignificant difference in both groups $(p>0.05)$. Demographic characteristics, mean eosinophil scores, gastric juice ECP levels, serum ECP levels, and gastric juice/serum ECP ratios for both groups are presented in Table 1. Eosinophil scores, gastric juice ECP levels, and gastric juice/serum ECP ratios were apparently greater in group 1 than group $2(p<0.01)$. Serum ECP levels were higher in the H. pylori-positive group than the $H$. pylori-negative group, although a statistically significant difference was not present $(p>0.05)$.

The age, sex, mean eosinophil scores, gastric juice ECP levels, serum ECP levels, gastric juice/serum ECP ratios of group $1 \mathrm{a}$ and group $1 \mathrm{~b}$ are presented in Table 2. Both the age and sex distribution had an insignificant difference between the two groups $(p>0.05)$. There was no significant difference in gastric eosinophil scores, gastric juice ECP levels, serum ECP levels, and gastric/serum ECP ratios between group $1 \mathrm{a}$ and group $1 \mathrm{~b}(p>0.05)$.

In a comparison of group $1 \mathrm{a}$ and group $1 \mathrm{~b}$ with group 2, gastric eosinophil scores, gastric juice ECP levels, gastric juice/serum ECP ratios were greater in both group 1 subgroups than in group $2(p<0.01)$. There was no significant difference between groups according to the serum ECP levels $(p>0.05)$. 
Helicobacter pylori-associated chronic gastritis and gastric ulcer

Table 1. Demographic characteristics, mean eosinophil score, gastric juice ECP level, serum ECP level and gastric juice/serum $\mathrm{ECP}$ ratio in $H$. pylori presence

\begin{tabular}{lccc}
\hline Parameter & Group 1 & Group 2 & $p$ value \\
\hline Subjects $(n)$ & 44 & 20 & \\
Mean age (years) & $43.2 \pm 11.3(20-60)$ & $42.5 \pm 10.1(22-54)$ & Not significant \\
Sex (male/female) & $25 / 19$ & $11 / 9$ & Not significant \\
Eosinophil score & $1.14 \pm 0.95$ & $0.35 \pm 0.59$ & $<0.01$ \\
Gastric juice ECP $(\mu \mathrm{g} / \mathrm{l})$ & $54.8 \pm 51.6$ & $19.1 \pm 18.6$ & $<0.01$ \\
Serum ECP $(\mu \mathrm{g} / \mathrm{l})$ & $19.7 \pm 20.1$ & $14.1 \pm 8.1$ & Not significant \\
Gastric juice/serum ECP ratio & $4.24 \pm 4.06$ & $1.24 \pm 1.01$ & $<0.01$
\end{tabular}

Group $1=$ H. pylori positive, Group $2=$ H. pylori negative.

\section{Discussion}

H. pylori is the most common bacterial infection worldwide. It is estimated that $60 \%$ of the world's population is infected by this microorganism. H. pylori is generally acquired in childhood and causes lifelong chronic gastritis unless initial acute gastritis is adequately managed. ${ }^{24,25}$ Approximately $20 \%$ of persons infected by $H$. pylori develop peptic ulcer disease in some period of their lifespan. ${ }^{5}$ Antral biopsies of individuals infected with $H$. pylori show focal epithelial cell damage as well as an inflammatory infiltrate in the lamina propria. This infiltrate consists of polymorphonuclear leukocytes, eosinophils, and mononuclear cells. ${ }^{7,24-29}$ Inflammatory response is pivotal in the epithelial dysfunction and mucosal injury caused by $H$. pylori. H. pylori stimulates the release of a variety of inflammatory mediators both directly by bacterial products such as vacuolating cytotoxin, lipopolysaccharide, neutrophil-activating factor and porins, and indirectly as a result of interaction with gastric epithelial cells. ${ }^{6,8,28,30}$ The role of eosinophils in the pathogenesis of $H$. pylori-associated gastritis and ulcer is not clearly explained.

The present study provides some evidence of an association between gastric eosinophil infiltration, gastric juice ECP and serum ECP levels in H. pylori infection and gastric ulcer disease.

Eosinophils play a role in many disorders, such as allergic, immunologic, and malignant diseases. ${ }^{9-11}$ Eosinophil granulocytes, predominantly tissue-dwelling cells, are normally present in low numbers in healthy gut mucosa. ${ }^{14,15}$ A possible role of the eosinophil in several intestinal diseases has been suggested. Patients with celiac disease have been shown to have prominent infiltration of eosinophils in the lamina propria, and activation of eosinophils was suggested by the release of ECP in the tissue and lumen of the intestine. ${ }^{31}$ The eosinophil may also be a major actor in the pathogenesis of inflammatory bowel disease because bowel biopsies from patients with inflammatory bowel disease have demonstrated an infiltration of eosinophils in the lamina propria and marked extracellular deposits of ECP. ${ }^{10,14,18,32}$ Moreover, eosinophilic gastrointestinal tract infiltration is encountered in food allergies and eosinophilic gastroenteritis. $^{12,14,15}$

The presence of eosinophils is assumed as a protective mechanism of unspecific mucosal immunity response against bacteria and parasites. ${ }^{11,15}$ Since eosinophil granules contain many proinflammatory and cytotoxic mediators, their protective role has become controversial. ${ }^{14}$ Activation of eosinophils seems to contribute to the pathophysiology of several inflammatory conditions. ${ }^{18,19,32}$ The role of the eosinophil granulocyte in the inflammatory reaction still remains obscure. One of the major constituents of the granule matrix is the eosinophil cationic protein. It is not only a strong helminthotoxic mediator, but it can also turn its destructive mechanisms against the host by cytotoxicity toward a variety of target cells including epithelial cells, smooth muscle cells, and nerve cells. ${ }^{10,14,17}$

We found that gastric mucosal eosinophil infiltration and the gastric juice ECP level were apparently greater in $H$. pylori-infected subjects. According to

Table 2. Demographic characteristics, mean eosinophil scores, gastric juice ECP level, serum ECP level and gastric juice/ serum ECP ratio in $H$. pylori-positive patients according to the presence or absence of gastric ulcer

\begin{tabular}{lccc}
\hline Parameter & Group 1a & Group 1b & $p$ value \\
\hline Subjects $(n)$ & 21 & 23 & Not significant \\
Mean age (years) & $41.1 \pm 10.7(20-60)$ & $45.2 \pm 11.7(29-59)$ & Not significant \\
Sex (male/female) & $12 / 9$ & $13 / 10$ & Not significant \\
Eosinophil score & $1.29 \pm 0.85$ & $1.02 \pm 1.4$ & Not significant \\
Gastric juice ECP $(\mu \mathrm{g} / \mathrm{l})$ & $56.51 \pm 47.1$ & $53.3 \pm 56.6$ & Not significant \\
Serum ECP $(\mu \mathrm{g} / \mathrm{l})$ & $20.5 \pm 19.3$ & $19.1 \pm 21.1$ & Not significant \\
Gastric juice/serum ECP ratio & $4.64 \pm 4.54$ & $3.88 \pm 3.63$ & \\
\hline
\end{tabular}

Group $1 \mathrm{a}=H$. pylori positive, gastric ulcer present.

Group $1 \mathrm{~b}=H$. pylori positive, gastric ulcer absent. 
the serum ECP level, however, no significant difference between two groups was found. On the other hand, gastric juice/serum ECP ratios were greater in patients infected by $H$. pylori. We failed to find any significant difference in regard to gastric mucosal eosinophil infiltration, gastric juice ECP levels, serum ECP levels and gastric juice/serum ECP ratios between those patients having gastric ulcer disease and those having not.

There are inadequate data in the literature on the role of eosinophil-associated ECP on diseases caused by $H$. pylori. In a study by McGovern et al. ${ }^{21}$ eosinophilic infiltration and degranulation in gastric mucosa were investigated histopathologically in H. pylori infection, and eosinophilic infiltration and degranulation in gastric mucosa were greater in patients with H. pylori gastritis. Berstad et al. ${ }^{33}$ in their study revealed that gastric juice ECP concentration was apparently greater in $H$. pylori-positive patients than the negative ones. We also found in accordance with the aforementioned studies that eosinophil infiltration in gastric mucosa and gastric juice ECP levels increased in $H$. pylori-positive patients. Ojetti et al. ${ }^{34}$ assessed serum/gastric juice ECP levels and gastric mucosal eosinophil infiltration in idiopathic chronic urticaria patients infected or not with $H$. pylori and evaluated the modification after bacterium eradication. However, they found that H. pylori infection affects gastric juice ECP and eosinophil infiltration of only idiopathic chronic urticaria patients.

As a result, it has been demonstrated that eosinophil infiltration in gastric mucosa and ECP levels in the gastric juice are increased in $H$. pylori-positive patients whereas serum ECP levels do not change significantly. No apparent difference was found in eosinophilic infiltration in gastric mucosa, gastric juice and serum ECP levels between patients with and without gastric ulcer. This result, although it supports the role of eosinophils and eosinophilderived ECP in inflammatory changes in chronic gastritis, suggests that these two factors do not contribute to gastric ulcer disease development.

\section{References}

1. Bertram TA, Murray PD, Morgan DR, Jerdak G, Yang P, Czinn S. Gastritis associated with infection by Helicobacter pylori in humans: geographical differences. Scand J Gastroenterol Suppl 1991; 181: 1-8.

2. Wyle FA. Helicobacter pylori: current perspectives. J Clin Gastroenterol 1991; 13 (Suppl 1): 114-124.

3. Tytgat GN, Noach L, Rauws EA. Helicobacter pylori. Scand J Gastroenterol Suppl 1991; 187: 1-8.

4. Takenaka $\mathrm{R}$, Yokota $\mathrm{K}$, Mizuno $\mathrm{M}$, et al. Serum antibodies to Helicobacter pylori and its heat-shock protein 60 correlate with the response of gastric mucosa-associated lymphoid tissue lymphoma to eradication of $H$. pylori. Helicobacter 2004; 9: 194-200.

5. Blaser MJ. Not all Helicobacter pylori strains are created equal: should all be eliminated? Lancet 1997; 349: 1020-1022.

6. Crabtree JE. Role of cytokines in pathogenesis of Helicobacter pyloriinduced mucosal damage. Dig Dis Sci 1998; 43: 46-55.

7. Bodger K, Crabtree JE. Helicobacter pylori and gastric inflammation. $\mathrm{Br}$ Med Bull 1998; 54: 139-150.
8. Bayraktaroglu T, Aras AS, Aydemir S, et al. Serum levels of tumor necrosis factor-alpha, interleukin- 6 and interleukin- 8 are not increased in dyspeptic patients with Helicobacter pylori-associated gastritis. Mediators Inflamm 2004; 13: 25-28.

9. Weller PF. The immunobiology of eosinophils. N Engl J Med 1991; 324: $1110-1118$.

10. Saitoh O, Kojima K, Sugi K, et al. Fecal eosinophil granule-derived proteins reflect disease activity in inflammatory bowel disease. $\mathrm{Am} \mathrm{J}$ Gastroenterol 1999; 94: 3513-3520.

11. Rothenberg ME. Eosinophilia. N Engl J Med 1998; 338: 1592-1600.

12. Levy AM, Kita K. The eosinophil in gut inflammation: effector or director? Gastroenterology 1996; 110: 952-954.

13. Bischoff SC, Mayer J, Nguyen QT, Stolte M, Manns MP. Immunnohistological assessment of intestinal eosinophil activation in patients with eosinophilic gastroenteritis and inflammatory bowel disease. $A m J$ Gastroenterol 1999; 94: 3521-3529.

14. Winterkamp S, Raithel M, Hahn EG. Secretion and tissue content of eosinophil cationic protein in Crohn's disease. J Clin Gastroenterol 2000; 30: $170-175$.

15. Talley NJ, Kephart GM, McGovern TW, Carpenter HA, Gleich GJ. Deposition of eosinophil granule major basic protein in eosinophilic gastroenteritis and celiac disease. Gastroenterology 1992; 103: 137-145.

16. Miyasato M, Tsuda S, Nakama T, et al. Serum levels of eosinophil cationic protein reflect the state of in vitro degranulation of blood hypodense eosinophils in atopic dermatitis. J Dermatol 1996; 23: $382-$ 388.

17. Venge P, Bystrom J. Eosinophil cationic protein (ECP). Int J Biochem Cell Biol 1998; 30: 433-437.

18. Peterson CG, Eklund E, Taha Y, Raab Y, Carlson M. A new method for the quantification of neutrophil and eosinophil cationic proteins in feces: establishment of normal levels and clinical application in patients with inflammatory bowel disease. Am J Gastroenterol 2002; 97: 17551762 .

19. Giembycz MA, Lindsay MA. Pharmacology of the eosinophil. Pharmacol Rev 1999; 51: $213-340$.

20. Galli SJ. New concepts about the mast cell. $N$ Engl J Med 1993; 328: $257-265$.

21. McGovern TW, Talley NJ, Kephart GM, Carpenter HA, Gleich GJ. Eosinophil infiltration and degranulation in Helicobacter pylori-associated chronic gastritis. Dig Dis Sci 1991; 36: 435-440.

22. Morris A, Nicholson G. Ingestion of Campylobacter pyloridis causes gastritis and raised fasting gastric pH. Am J Gastroenterol 1987; 82: 192 199.

23. Frommer DJ, Carrick J, Lee A, Hazell SL. Acute presentation of Campylobacter pylori gastritis. Am J Gastroenterol 1988; 83: 1168-1171.

24. Pounder RE, Ng D. The prevalence of Helicobacter pylori infection in different countries. Aliment Pharmacol Ther 1995; 9 (Suppl 2): 33-39.

25. Everhart JE. Recent developments in the epidemiology of Helicobacter pylori. Gastroenterol Clin North Am 2000; 29: 559-578.

26. Niemela S, Karttunen $T$, Kerola $T$. Chronic gastritis in patients with gastric ulcer; a 10-year follow-up. Scand J Gastroenterol 1995; 30: 428433.

27. Yang HB, Sheu BS, Su IJ, Chien CH, Lin XZ. Clinical application of gastric histology to monitor treatment of dual therapy in $H$. pylori eradication. Dig Dis Sci 1997; 42: 1835-1840.

28. Fiocca R, Luinetti O, Villani L, Chiaravalli AM, Capella C, Solcia E. Epithelial cytotoxicity, immune responses, and inflammatory components of Helicobacter pylori gastritis. Scand J Gastroenterol Suppl 1994; 205: $11-21$.

29. Whitney AE, Guarner J, Hutwagner L, Gold BD. Helicobacter pylori gastritis in children and adults: comparative histopathologic study. Ann Diagn Pathol 2000; 4: 279-285.

30. Crabtree JE. Gastric mucosal inflammatory responses to Helicobacter pylori. Aliment Pharmacol Ther 1996; 10 (Suppl 1): 29-37.

31. Hallgren R, Colombel JF, Dahl R, et al. Neutrophil and eosinophil involvement of the small bowel in patients with celiac disease and Crohn's disease: studies on the secretion rate and immunohistochemical localization of granulocyte granule constituents. Am J Med 1989; 86: 56-64.

32. Raab Y, Fredens K, Gerdin B, Hallgren R. Eosinophil activation in ulcerative colitis: studies on mucosal release and localization of eosinophil granule constituents. Dig Dis Sci 1998; 43: 1061-1070.

33. Berstad K, Berstad A, Jr, Sjodahl R, Weberg R, Berstad A. Eosinophil cationic protein and phospholipase A2 activity in human gastric juice, With emphasis on Helicobacter pylori status and effects of antacids. Scand J Gastroenterol 1992; 27: 1011-1017.

34. Ojetti V, Armuzzi A, De Luca A, et al. Helicobacter pylori infection affects eosinophilic cationic protein in the gastric juice of patients with idiopathic chronic urticaria. Int Arch Allergy Immunol 2001; 125: 6672

\section{Received 11 August 2004}

Accepted 10 September 2004 


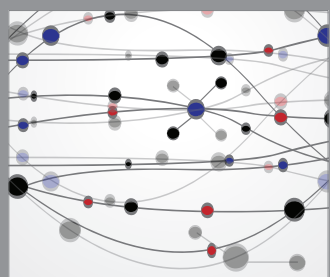

The Scientific World Journal
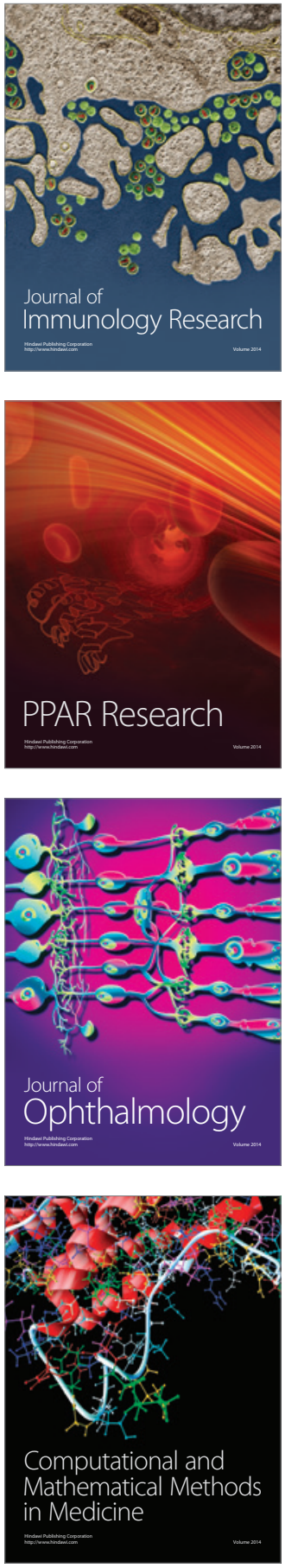

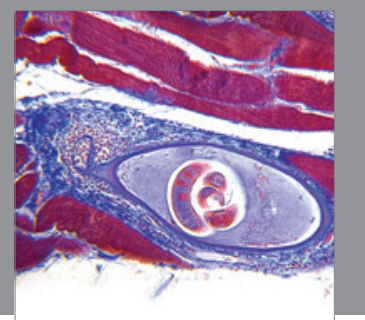

Gastroenterology

Research and Practice
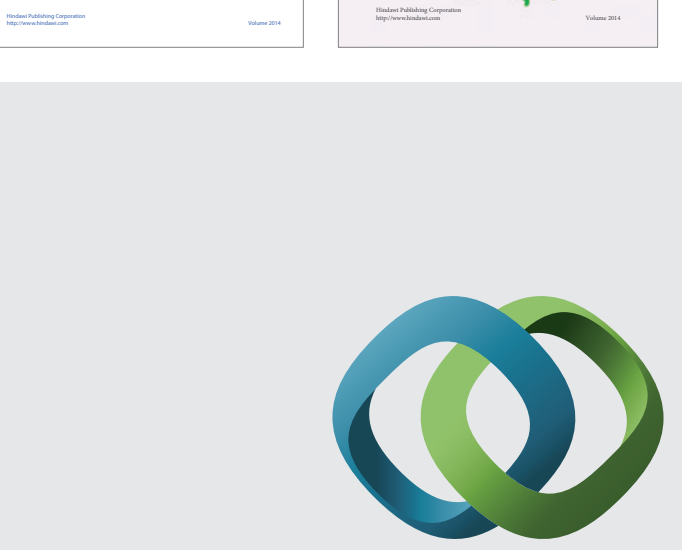

\section{Hindawi}

Submit your manuscripts at

http://www.hindawi.com
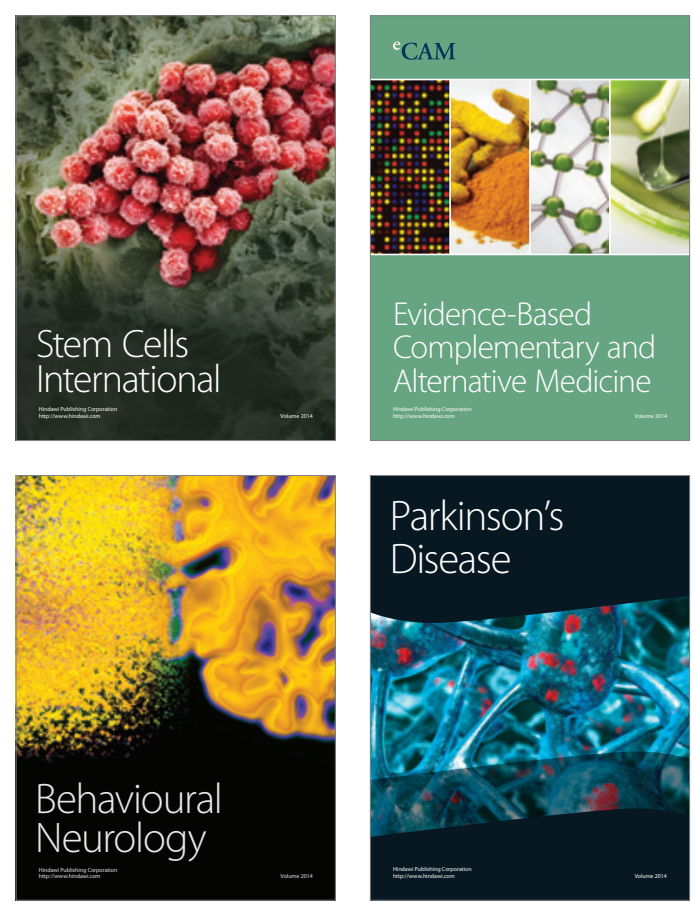

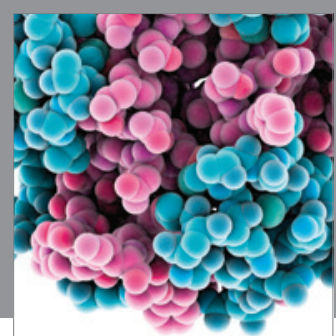

Journal of
Diabetes Research

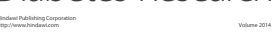

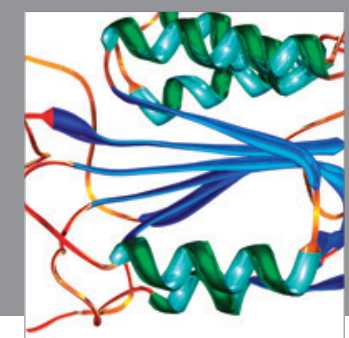

Disease Markers
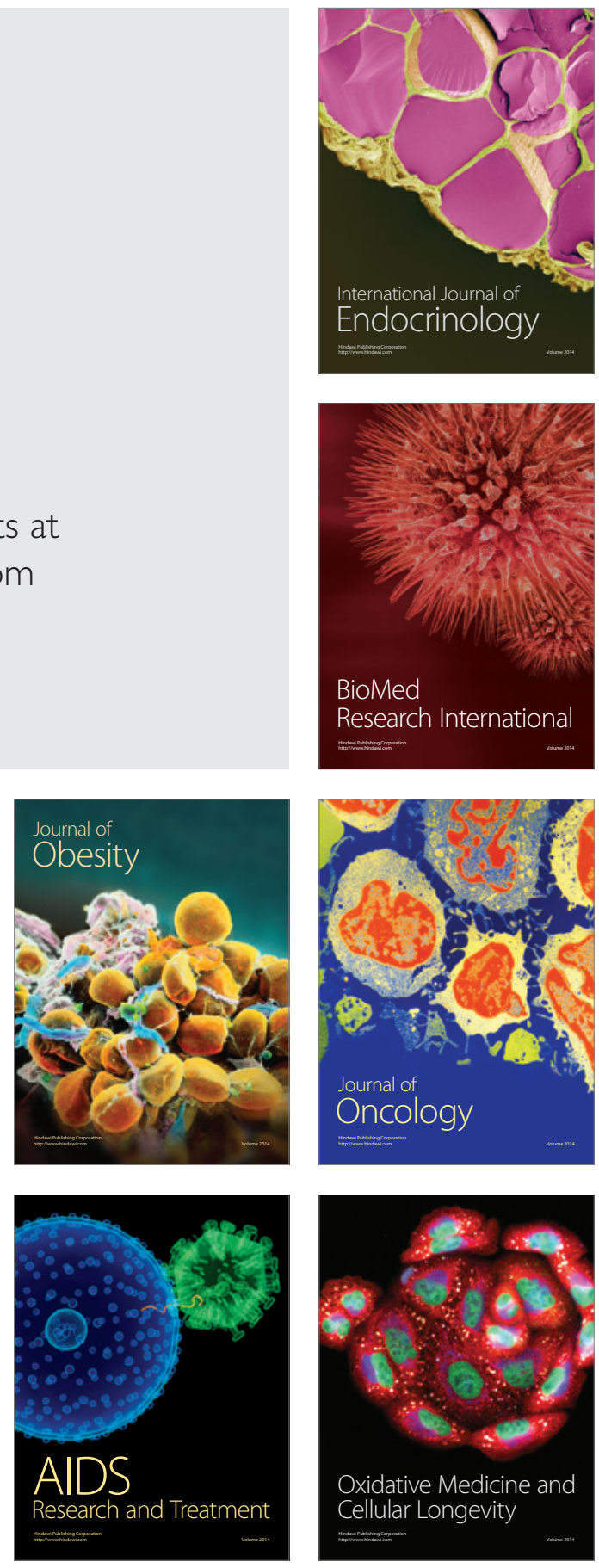